\title{
BMJ Open Implementing the RISE second victim support programme at the Johns Hopkins Hospital: a case study
}

\author{
Hanan Edrees, ${ }^{1,2}$ Cheryl Connors, ${ }^{3,4}$ Lori Paine, ${ }^{3,4}$ Matt Norvell, ${ }^{3}$ Henry Taylor, ${ }^{1}$ \\ Albert $\mathrm{W} \mathrm{Wu}^{1,4}$
}

To cite: Edrees $\mathrm{H}$, Connors C, Paine L, et al. Implementing the RISE second victim support programme at the Johns Hopkins Hospital: a case study. BMJ Open 2016;6: e011708. doi:10.1136/ bmjopen-2016-011708

- Prepublication history and additional material is available. To view please visit the journal (http://dx.doi.org/ 10.1136/bmjopen-2016011708).

Received 18 March 2016 Revised 23 August 2016 Accepted 1 September 2016

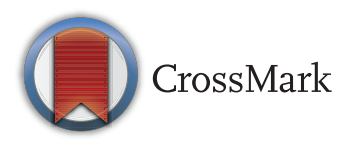

1Johns Hopkins Bloomberg School of Public Health, Baltimore, Maryland, USA ${ }^{2}$ National Guard Health Affairs, Quality Management/ King Abdullah International Medical Research Center/King Saud bin Abdulaziz University for Health Sciences, Riyadh, Kingdom of Saudi Arabia 3Johns Hopkins Hospital, Baltimore, Maryland, USA ${ }^{4}$ Johns Hopkins Armstrong Institute for Patient Safety and Quality, Baltimore, Maryland, USA

Correspondence to Dr Albert W Wu; awu@jhu.edu

\section{ABSTRACT}

Background: Second victims are healthcare workers who experience emotional distress following patient adverse events. Studies indicate the need to develop organisational support programmes for these workers. The RISE (Resilience In Stressful Events) programme was developed at the Johns Hopkins Hospital to provide this support.

Objective: To describe the development of RISE and evaluate its initial feasibility and subsequent implementation. Programme phases included (1) developing the RISE programme, (2) recruiting and training peer responders, (3) pilot launch in the Department of Paediatrics and (4) hospital-wide implementation.

Methods: Mixed-methods study, including frequency counts of encounters, staff surveys and evaluations by RISE peer responders. Descriptive statistics were used to summarise demographic characteristics and proportions of responses to categorical, Likert and ordinal scales. Qualitative analysis and coding were used to analyse open-ended responses from questionnaires and focus groups.

Results: A baseline staff survey found that most staff had experienced an unanticipated adverse event, and most would prefer peer support. A total of 119 calls, involving $\sim 500$ individuals, were received in the first 52 months. The majority of calls were from nurses, and very few were related to medical errors $(4 \%)$. Peer responders reported that the encounters were successful in $88 \%$ of cases and $83.3 \%$ reported meeting the caller's needs. Low awareness of the programme was a barrier to hospital-wide expansion. However, over the 4 years, the rate of calls increased from $\sim 1-4$ calls per month. The programme evolved to accommodate requests for group support.

Conclusions: Hospital staff identified the need for a multidisciplinary peer support programme for second victims. Peer responders reported success in responding to calls, the majority of which were for adverse events rather than for medical errors. The low initial volume of calls emphasises the importance of promoting awareness of the value of emotional support and the availability of the programme.

\section{Strengths and limitations of this study}

- Describes one of the earliest organisational programmes to support second victims, by the team that originated the concept.

- Provides detailed description of the process of development and implementation.

- Provides assessment tools that can be used by other organisations.

- No systematic follow-up of caller outcomes.

- Relatively small sample sizes and some missing data.

\section{INTRODUCTION}

Adverse events bring to light system defects that can cause patient harm. In the past decade, healthcare organisations have adopted standardised procedures to investigate events, and staff have become more aware of system defects. ${ }^{1}$ However, organisations often fail to recognise the impact of adverse events on healthcare providers who can suffer emotional distress as 'second victims' of the same incidents that harm patients. $^{2-4}$

At the Johns Hopkins Hospital ( JHH), adverse patient-related events are reported to managers and the online incident reporting system; some are debriefed with staff and a few are investigated. Patient safety leaders recognised a gap in the ability of the institution to provide consistent and timely support to second victims-healthcare providers who are traumatised by patient adverse events. ${ }^{5}$ In 2010, leaders in patient safety, risk management and clinical departments began meeting to discuss the magnitude and importance of the problem, current infrastructure to support healthcare providers, stories and experiences, and strategies to improve the system. This process led to the establishment of the RISE (Resilience in Stressful Events) peer support programme. 
Although there are a few published descriptions of organisational peer support programmes, there has been little documentation of the steps involved in their development. ${ }^{6} 7$ Additionally, there are limited evaluations of the feasibility, implementation and effectiveness of these programmes. ${ }^{8}$ The aim of this paper was to describe the development of RISE at the JHH, and the initial evaluation of a pilot test of the programme, and its hospital-wide implementation. It is hoped that this information will help other institutions establish staff support programmes of their own.

\section{Development of RISE programme}

The JHH is a 1075-licensed bed, urban, academic medical centre established in 1889. After the occurrence of a significant adverse patient-related event in the JHH Department of Paediatrics in 2001, staff struggled to cope and were affected personally and professionally. Subsequent review helped hospital leaders recognise the need to provide a programme supporting staff following adverse events. In 2009, the JHH Patient Safety Department took initial steps to establish an organisational support programme for second victims. Development initially took place in four phases: (1) programme development (January 2010-ongoing), (2) recruitment and training of peer responders (June 2011-ongoing), (3) RISE pilot in the Department of Paediatrics (November 2011-June 2012) and (4) hospital-wide expansion of RISE (June 2012-March 2016).

A multidisciplinary Programme Development Team was created to lead the strategic planning and implementation of RISE. To understand the types of support needed, the team developed a survey that was administered in June 2010 at a presentation on second victims by one of the team members (AWW) at the First Annual Johns Hopkins Patient Safety Summit. Two-thirds of the respondents to this survey reported experiencing emotional distress following an unanticipated adverse event, and more than half of these respondents had reached out for support from a peer or colleague. ${ }^{5}$ Respondents endorsed the need for a hospital-sponsored peer support programme to benefit second victims.

\section{Development of RISE (phases I-IV) \\ Phase I: RISE programme Development Team and the RISE mission}

The RISE leadership team comprised six members: the Director of Patient Safety (LP), a physician faculty member (AWW), a risk manager (Jeff Natterman), a patient safety researcher (HE), a nurse manager (CC) and a hospital chaplain (MN) (see figure 1 for timeline). The leadership team developed a work plan, logistics and procedures for the programme, identified additional team members to provide peer support, and determined the training and resources necessary to support these efforts. The team met twice a month beginning in January 2010.
The RISE team of peer responders was established in the fall of 2011. A long-term goal of the programme was to foster a culture in which all employees were resilient and mutually supportive before, during and after stressful events (figure 2). A peer support programme led by healthcare workers was a preferred option expressed by staff, given that peers were viewed as understanding clinical issues and peer support had been shown to be effective, economically viable and sustainable. ${ }^{9}{ }^{10}$ RISE was intended to provide timely access to support employees' immediate needs to complement the services being offered by the existing employee assistance programme (Faculty And Staff Assistance Programme-FASAP). 89

\section{Procedures: responding to second victims}

After the occurrence of a stressful, patient-related event - such as an adverse event, medical error, death, unexpected outcome or non-accidental trauma-the healthcare worker involved or his/her colleague activates a RISE call by paging the RISE team. The RISE pager number and an intranet call button activate the RISE pager. The on-call RISE peer responder responds to the pager by calling back within $30 \mathrm{~min}$, and planning a meeting (encounter) with the caller-ideally within the next 12 hours. The term 'peer responder' does not imply that the responder shares the same professional discipline as the caller.

In the encounter, the peer responder actively listens to the second victim and provides psychological first aid (PFA) and emotional support. The encounter explicitly focuses on the emotions of the employee rather than the details of the incident. At the end of the encounter, the peer responder offers a list of current organisational resources that might be helpful for continued healing, such as the employee assistance programme, community counselling or exercise.

All interactions between the second victim and the peer responder are confidential. RISE is based organisationally within the Armstrong Institute for Patient Safety and Quality at the Johns Hopkins, and discussions between a RISE responder assisting a second victim are presumed to be covered by patient safety privilege under Maryland State Law, despite the fact that there has never been a legal test case. ${ }^{11}$ The only exception is if the caller indicates the potential for imminent harm to self or others, in which case the peer responder assists the caller with the necessary resources obtained to mitigate harm. After the encounter, the peer responder activates a debriefing, in which he/she facilitates a session to receive support from the other members of the RISE team and to provide a learning opportunity for other members.

\section{Phase II: recruiting and training of RISE peer responders Recruitment}

Initially, peer responders were recruited based on recommendations from organisational leaders, based on their known ability to provide support to colleagues. 


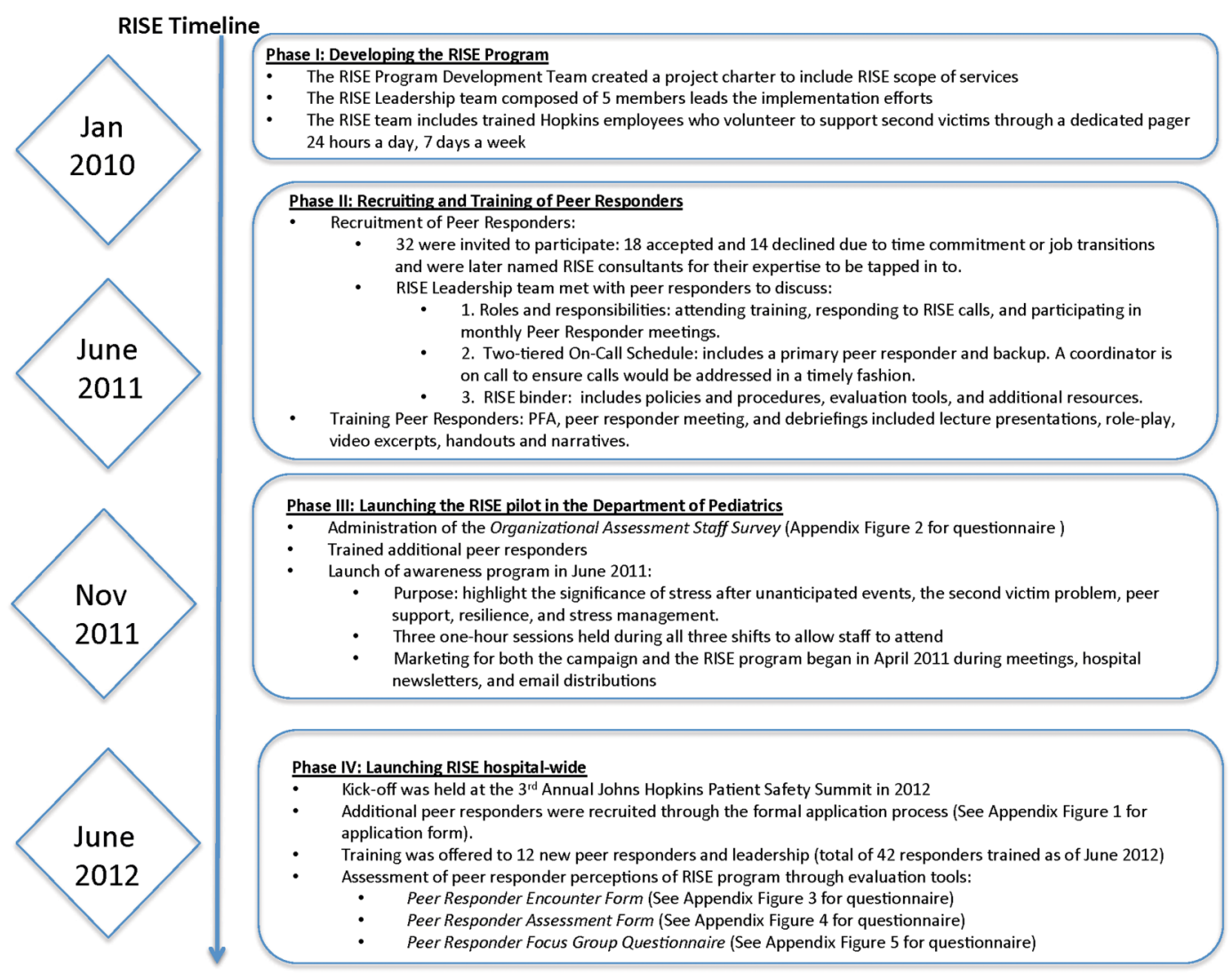

Figure 1 RISE timeline. RISE, Resilience In Stressful Events.

RISE Mission

To provide timely support to employees who encounter stressful, patient-related events

RISE Team Objectives

1. Increase awareness of the second victim phenomenon in healthcare's highrisk environment

2. Provide multi-disciplinary, one-to-one or group, peer support in a nonjudgmental environment

3. Equip managers and employees with healthy coping strategies to promote well-being:

a. Offer tools to support managers in their roles when responding to second victim events

b. Provide first responder tips to all employees before, during, and after an event

4. Reassure and guide employees to continue thriving in their roles

a. Develop a non-punitive approach to handling stressful patient-related events

b. Define policies and procedures for the RISE program

Figure 2 RISE mission and objectives. RISE, Resilience In Stressful Events.

Subsequent groups of responders were self-nominated and asked to complete a structured application and to submit letters of recommendation. These applications were reviewed by the executive committee of RISE. Most of the peer responders from the initial group were registered nurses $(63.3 \%)$, and half of the peer responders were from the Department of Paediatrics $(50.0 \%)$ (table 1). A total of 42 peer responders have been trained, with 30 currently active, including 11 of the original cadre of 18 responders who are still on the team.

\section{Training}

To serve as a peer responder, team members were required to attend PFA training, RISE team meetings and debriefings after encounters. PFA is a form of early intervention to address emotional distress. ${ }^{10}$ Dr George Everly, the developer of RAPID-PFA (Reflective listening, Assessment, Prioritisation, Intervention and Disposition), offered a 6-hour training through the Johns Hopkins Center for Public Health Preparedness. ${ }^{12} 13$ The first training session was offered in September 2011, with a total of eight training sessions offered on a periodic basis. Hour-long peer responder meetings were conducted monthly and included discussions of the published literature, practice delivering PFA and sharing of second victim encounters. Material was presented in the form of lectures, storytelling sessions, role-play exercises and group discussions. Debriefings occurred after each RISE encounter and provided collective learning opportunities for peer responders to reflect, mentor, support one another and gain vicarious experience about calls. These meetings took place for an hour.

Refresher training sessions are provided on an annual basis at RISE team retreats. Ongoing training is gained through the debriefings within the RISE team and at monthly meetings where cases are discussed and skills are practised. 


\begin{tabular}{lr} 
Table $1 \quad$ Characteristics of peer responders \\
\hline Peer responder demographics $\mathbf{( n = 3 0 )}$ & $\mathbf{n}(\%)$ \\
\hline Gender & $26(86.7)$ \\
Female & $4(13.3)$ \\
Male & \\
Discipline & $19(63.3)$ \\
Nursing & $3(10.0)$ \\
Administration & $2(6.7)$ \\
Patient safety & $2(6.7)$ \\
Child life & $1(3.3)$ \\
Medicine & $1(3.3)$ \\
Social work & $1(3.3)$ \\
Respiratory therapy & $1(3.3)$ \\
Chaplain & $15(50.0)$ \\
Department and unit & $9(30.0)$ \\
Paediatrics & $3(10.0)$ \\
Adult medicine & $2(6.7)$ \\
Patient safety & $1(3.3)$ \\
JHH & \\
Bone marrow transplant specialist & \\
Other units represented: oncology, psychiatry, & \\
OB/GYN, labour and delivery, surgery & \\
\hline JHH, Johns Hopkins Hospital. &
\end{tabular}

\section{Phase III: launching the RISE pilot in the Department of} Paediatrics

To introduce the programme, an awareness campaign was launched on 24 June 2011 in the 205-bed Johns Hopkins Children's Center. In November 2011, RISE began a pilot programme there based on a strong commitment by the Paediatric Department's leadership to RISE.

\section{Phase IV: hospital-wide expansion of the RISE programme}

On 21 June 2012, 7 months after the launch of the Paediatrics pilot, the RISE programme received approval from hospital leadership to expand to the entire hospital. The announcement was made at the annual Patient Safety Summit, preceded by a presentation to help staff understand the purpose of the team as well as contact information for RISE.

In this phase of the programme, members of the RISE team developed a two-tiered call system, whereby two peer responders were on call at any given time. The first peer responder responds to the RISE pager, while the second one provides back-up for first if additional support is necessary. The RISE director is available to provide additional support if technical or administrative issues arise. Using this system, staff members are able to call the RISE team anonymously. If the first responder and caller happen to work on the same unit, the call can be handled by the second on-call responder.

To increase the volume of calls, additional efforts were taken to promote awareness among hospital staff members. This included the development of a website, featuring promotional videos explaining the function and benefits of this service, publicity through internal publications, screen savers that cycle continuously on public computer screens, presentations to targeted departments and units, and recruitment of unit-level champions.

Approximately $56 \%$ of callers requested group, rather than individual, support. In the group RISE calls, the inciting incidents were almost uniformly related to patient death unrelated to medical errors and were often known to the hospital community, and some even to the public. RISE encounters for groups tended to be longer than individual sessions. The groups have a variety of multidisciplinary compositions and range from 5 to 25 attendees depending on the number of employees affected. To make sure that members of the group received enough attention, it was required that group requests be attended by at least two responders.

Financial support for the RISE programme was provided by the Armstrong Institute which assures safety and quality for the health system. The budget supports 0.30 full-time equivalent (FTE) of the programme director (CC) who emerged as the operational leader of the team.

\section{METHODS \\ Study design}

This evaluation of a novel hospital programme used a mixed-methods design that included a staff survey, peer responder self-evaluations and a focus group of peer responders (see online supplementary appendix). The project was approved by the Johns Hopkins Institutional Review Board.

Design of the evaluation reflected the need to assure confidentiality for callers, which programme leaders thought, was necessary for distressed healthcare workers to use the programme. There was also a concern by the institution that records of encounters might be potentially admissible as evidence in a malpractice suit. For that reason, the programme was designed not to collect identifying information from callers, or follow up systematically with them. It was also considered insensitive to ask distressed callers to complete a satisfaction survey at the end of the encounter. Therefore, our measures were collected from the perspective of the peer responders after their encounters with callers.

\section{Participants and procedures}

Before launching the pilot programme (phase III), frontline staff in the Department of Paediatrics $(n=144)$ completed the Organisational Staff Assessment Survey and were asked to assess their perceptions of the second victim problem and implementation of a second victim support programme (table 2). All faculty and staff working in the department were included in the survey. Peer responders in phase IV returned the Peer Responder Encounter and the Assessment Form $(\mathrm{n}=80$, 57 complete forms). For group encounters, the lead peer responder was asked to complete the Peer 
Table 2 Organisational Staff Assessment Survey-participant characteristics and staff experience in seeking support

\begin{tabular}{lr}
\hline Profession $(\mathbf{n}=\mathbf{1 4 4 )}$ & $\mathbf{n}(\%)$ \\
\hline Registered nurse & $102(70.8)$ \\
Pharmacist & $14(9.7)$ \\
Clinical social worker & $10(6.9)$ \\
Child life specialist & $6(4.2)$ \\
Clinical technician & $3(2.1)$ \\
Clinical therapist & $2(1.4)$ \\
Attending/staff physician & $1(0.7)$ \\
Administrator & $3(2.1)$ \\
Environmental support & $1(0.7)$ \\
Other & $2(1.4)$ \\
Number of years in healthcare $(\mathbf{n = 1 4 2 )}$ & \\
Less than 1 year & $7(4.9)$ \\
$1-5$ years & $47(33.1)$ \\
6-10 years & $26(18.3)$ \\
11-20 years & $33(23.2)$ \\
\hline
\end{tabular}

Survey questions (number of responses)

Per cent agree

Directly involved in an unanticipated adverse event $(n=143)$

66.4

Experience any problems, such as anxiety, depression, or concern about ability to perform $\quad 77 \quad 57.9$ job, as a result of this event $(n=133)$

Reached out for support or talked to someone about the event $(n=128)$

70.3

If you reached out for support, who did you talk to (of $n=90)$ (one or more response per respondent)

\begin{tabular}{|c|c|}
\hline Colleague on the unit & 32.5 \\
\hline Colleague off the unit & 11.3 \\
\hline Spouse/significant other & 22.2 \\
\hline Friend & 18.2 \\
\hline Manager/supervisor & 11.3 \\
\hline Counsellor & 2.0 \\
\hline Chaplain/clergy & 1.5 \\
\hline Risk manager/attorney & 1.0 \\
\hline \multicolumn{2}{|c|}{ Staff perceptions on features and services of an organisational second victim support programme } \\
\hline \multicolumn{2}{|l|}{ Preferred individuals to provide support $(n=138)$} \\
\hline Multidisciplinary peer group & 68.7 \\
\hline Nurse manager & 15.5 \\
\hline Pastoral care & 13.3 \\
\hline Counsellor & 1.7 \\
\hline Social work & 0.9 \\
\hline \multicolumn{2}{|l|}{ Type of support $(n=138)$} \\
\hline Individual support & 70.7 \\
\hline Group support & 29.3 \\
\hline \multicolumn{2}{|l|}{ Preferred timeframe to access support $(n=135)$} \\
\hline As soon as the event happened & 12.7 \\
\hline A few hours after the event happened & 25.4 \\
\hline A couple of days after the event took place & 48.2 \\
\hline A week after the event took place & 8.1 \\
\hline \multicolumn{2}{|l|}{ Other } \\
\hline Depends on the severity of the event & 3.6 \\
\hline When second victim felt comfortable to access support & 2.0 \\
\hline
\end{tabular}

Responder Encounter and Peer Responder Assessment forms after each encounter. A random sample of nine members of the peer responder team were invited to participate in the focus group discussion, of whom five were able to participate at the designated time.

\section{Measures and variables}

Organisational Staff Assessment Survey: It was used to collect data from healthcare professionals on the need for support of healthcare workers. Information collected included respondents' characteristics, respondents' 
personal experience as a second victim, and desired features and services of an organisational support programme.

Peer Responder Encounter Form: It was used by peer responders to provide de-identified information on the event and nature of the RISE call. 'De-identified' in this case meant that the information collected on the event could not be traced to a specific person or patient. Several items were based on the University of Missouri's forYOU Peer Responder Encounter Form (Scott, SD. Personal Communication forYOU Encounter Form-a survey developed by Sue Scott and the forYOU team at the University of Missouri, 2010).

Peer Responder Assessment Form: It was used by peer responders to evaluate the interaction with the caller after each encounter (see online supplementary appendix). All of the items were newly developed for this assessment in an effort to capture a minimal amount of information needed to evaluate the encounter and inform quality improvement. Information collected included a brief description of the encounter with the second victim, peer responder evaluation of the appropriateness of RISE training to respond to the specific call, the peer responder's experience in providing support to the caller(s), and their recommendations on how to improve the RISE programme. This form was not modified at the time of hospital-wide expansion.

Peer Responder Focus Group: The aim of the focus group discussion was to assess peer responder perceptions, confidence levels and self-assessed competence based on the RISE training they received. The interview guide also directed questions about the peer responders' own emotional distress when responding to a second victim.

\section{Data analysis}

We used descriptive statistics to summarise calls and participant demographic characteristics. We calculated proportions for the quantitative responses, which included categorical/multiple choice and Likert-type scale questions ( $1=$ strongly disagree; $5=$ strongly agree), ordinal scales and counts. Content analysis was conducted to assess the open-ended responses in the Organisational Staff Survey and the focus group transcript, using standard qualitative analysis methods. ${ }^{14}$ Each transcript was analysed by two members of the study team (HE and CC) first to get a global impression, then identifying and coding each meaning unit in the transcript. The contents of each meaning unit were abstracted and organised into groups with other units as themes emerged. The interview questions were compared to the transcript to refine this iterative analysis. Disagreements in coding were resolved by consensus.

\section{RESULTS}

Respondents to the Organisational Staff Assessment Survey were primarily registered nurses $(70.8 \%, \mathrm{n}=102)$, and most respondents had over 1 year of work experience in healthcare (table 2). Approximately $70 \%$ of respondents had been directly involved in an unanticipated adverse event, and $57.9 \%(\mathrm{n}=77)$ reported experiencing problems, such as anxiety or inability to perform their job, as a result of this event. Over two-thirds $(70.3 \%, \mathrm{n}=90)$ had reached out for support following the event (table 2).

When asked about potential second victim support programmes (table 2), most respondents $(68.7 \%, \mathrm{n}=95)$ indicated that they would prefer a multidisciplinary peer group to offer support. Others mentioned that they would prefer a nurse manager $(15.5 \%, \mathrm{n}=21)$ or pastoral care $(13.3 \%, \mathrm{n}=18)$. More than two-thirds $(70.7 \%, \mathrm{n}=97)$ preferred individual support to group support. Additionally, respondents preferred to access support soon after the event: as soon as it happened $(12.7 \%$, $\mathrm{n}=17$ ), a few hours after the event happened $(25.4 \%$, $\mathrm{n}=34$ ), a couple of days after the event happened $(48.2 \%, \mathrm{n}=66)$ and a week after the event took place $(8.1 \%, \mathrm{n}=11)$. Others indicated that timeliness of support desired depended on the severity of the event or their comfort level following the event.

\section{Description of calls}

There were a total of 119 calls. There were 12 calls during the Paediatrics pilot, 15 calls in year 2, 37 calls in year 3,40 calls in year 4 and 15 calls in the first 4 months of year 5 . Thus, the rate of calls was $\sim 1$ per month for the first year, 2 per month in the second year, 3 per month in the third year and 4 per month thereafter. Approximate proportions of callers by profession were as follows: nurse 56\%, nurse practitioner $2.5 \%$, multidisciplinary group $28.8 \%$, physician $16.2 \%$, other $6.3 \%$, not recorded $13 \%$ for 80 encounters.

The majority of incidents were related to adverse events, rather than medical errors. For 80 of the encounters for which the information was available, $45.0 \%$ included death of a patient, and $21.3 \%$ involved an adverse event. The remainders of calls were for other difficult situations, such as difficult decisions, burnout, staff assault, intrastaff conflicts and others. Only 4 of the 80 incidents were related to a clear-cut medical error. The average interaction lasted for $49 \mathrm{~min}$. A total of $43 \% \quad(\mathrm{n}=34)$ were one-to-one encounters, and $56 \%$ $(\mathrm{n}=44)$ were group sessions.

\section{Peer Responder Encounter and Assessment Forms}

All of the responders on the team responded to at least one call. Data were completed by peer responders for 80 of the 119 encounters between November 2011 and March 2016-a 67\% completion rate (table 3). The mean interaction length was $49 \mathrm{~min}$ (median $50 \mathrm{~min}$ ). Most of the callers were looking for support at the recommendation of their supervisors $(56.2 \%)$ with the remainder being self-referred. Less than $8 \%$ of the callers reported experiencing barriers with accessing the RISE team; the primary barrier was lack of awareness on how to access the programme. In phase IV, peer 
Table 3 Characteristics of RISE calls (number of RISE calls $=80$ )

n (\%)

\begin{tabular}{ll}
\hline Profession of second victim & $45(56.3)$ \\
RN & $23(28.8)$ \\
Multidisciplinary group & $13(16.3)$ \\
Physician & $2(3.8)$ \\
Nurse practitioner & $7(8.7)$ \\
Other (nurses' aide, respiratory & \\
technician, child psychology & \\
specialist, clinical customer service & \\
representative, CT scan staff) & \\
Not known & $11(13.8)$ \\
\hline Type of call & \\
Individual (one-on-one) & $34(42.5)$ \\
Group & $44(55.0)$ \\
Unknown & $2(2.5)$ \\
\hline Mean length of the interaction & 49 min (range: \\
& $10-120$ min) \\
\hline Referral sources & \\
Supervisor & $43(53.8)$ \\
Self & $17(21.3)$ \\
Peer & $9(11.3)$ \\
Nurse leader & $4(5.0)$ \\
Unknown & $7(8.8)$ \\
\hline RISE, Resilience In Stressful Events; RN, registered nurse.
\end{tabular}

responders' perceptions were also assessed on the programme structure and processes.

Peer responders believed that the RISE training enriched their interactions with callers. Role-play, focusing on key principles of peer response, has been identified as the most effective method for training. Additionally, roleplay provides a safe place for the responders to practise. Scenarios that have been actual encounters are often used so that responders can continue to learn and apply strategies, resulting in a positive future encounter. When call volume was low, anticipated scenarios were used to prepare responders. Responders reported higher comfort levels in responding to the second victim after the peer responder training compared to rating their overall competence in meeting the callers' needs (excellent or very good only $44.9 \%$ of the time).

Most of the peer responders $(84.3 \%)$ offered the caller additional support resources (table 4). Following the encounter, peer responders rated the success of the interaction to be either 'excellent' $(66.7 \%)$ or 'neutral' $(22.8 \%)$. Most believed that they met the second victims' expectations $(87.8 \%)$ and were satisfied with the interaction $(82.4 \%)$. Approximately $70 \%$ of the peer responders indicated that they themselves experienced little or no emotional distress after they offered support to the second victim.

Peer Responder Focus Group: The focus group discussion was conducted in April 2013 during a 90 min session. Nine peer responders were invited to participate in the focus group, and five participated, for a $55.6 \%$ response rate. Peer responders had varying levels of experience in responding to second victims and joined the RISE team at different times since the inception of the programme. Approximately three minutes was allocated for each peer responder to respond to each of the focus group questions.

Several themes emerged from the qualitative analysis of this session (table 5). Initial PFA training and ongoing training, such as the peer responder meetings and debriefings, were described as helpful in preparing peer responders. Most of the peer responders found the greatest value in the initial PFA training and in the ongoing skill-sharpening opportunities in the debriefings and monthly meetings. These aspects of training provided the peer responders with adequate skills to respond to a distressed employee. There was a desire for more training on how to facilitate group sessions comprising multiple disciplines and services, role-plays involving clinicians with different professional roles, and the development of 'key phrases' or scripts to be used at the beginning and at the end of an encounter. Some peer responders experienced higher levels of personal distress in providing group (rather than one-on-one) support. Recommendations for future training and education included (1) group support, (2) interdisciplinary approach in holding debriefings, (3) training focused on physicians as opposed to other providers, and (4) key phrases and scripts.

\section{DISCUSSION}

We describe the initial evaluation of RISE, a multidisciplinary peer support programme based within a large teaching hospital. The structure and features of RISE were guided by the results of an initial survey which suggested that such a programme would be preferred by workers who experienced stressful, patient-related events. Evaluation based on the self-reports of peer responders supported the success of most encounters with callers and the effectiveness of training-particularly role-playing exercises-in preparing them to support second victims. However, at the end of the pilot period, peer responders also identified the desire for additional training and education to increase their confidence and competence in responding to second victims. There were relatively few calls in the first year of operation. This may have been due, in part, to lack of staff awareness of RISE services or how to access them. In subsequent years, additional measures were taken to increase awareness and acceptance of the service. Concurrent with this, use of the programme has increased steadily, and in year 5 of the programme, the rate of calls is four times higher than during its pilot phase.

A strength of the RISE programme is that it was based on local staff perceptions of the second victim problem and existing resources-the Medically Induced Trauma Support Services (MITSS) Toolkit for Building a 
Table 4 Peer responder evaluation of RISE calls $(n=57)$

\begin{tabular}{llr}
\hline & $\mathbf{n}(\%)$ & Strongly agree \\
\cline { 2 - 3 } $\begin{array}{l}\text { Process-peer responder training and education } \\
\text { I felt comfortable listening to the second victim }\end{array}$ & \\
I felt comfortable responding to the second victim & $17(29.8)$ & $2(3.5)$ \\
I need additional training/experience as a peer responder & $23(40.4)$ & $1(1.8)$ \\
I am comfortable with my knowledge and skill as a peer responder & $20(35.1)$ & $1(1.8)$ \\
I am highly competent as a peer responder & $27(47.4)$ & $18(31.6)$ \\
I would be able to train other peer responders & $31(54.4)$ & $10(17.5)$ \\
Outcomes-peer responder overall experience and recommendations & $31(54.4)$ & $9(15.8)$ \\
I was able to offer the second victim additional helpful resources & $36(63.2)$ & $12(21.1)$ \\
I felt confident in offering the second victim additional resources & $35(61.4)$ & $11(19.3)$ \\
It was beneficial for the second victim to contact the RISE team & $27(47.4)$ & $25(43.9)$ \\
I met the second victim's expectations & $36(63.2)$ & $14(24.6)$ \\
I felt satisfied with how this encounter turned out & $32(56.1)$ & $15(26.3)$ \\
Overall success of the encounter & & Excellent \\
& & $38(66.7)$ \\
\hline RISE, Resilience In Stressful Events. & &
\end{tabular}

Clinician and Staff Support Program, and the pioneering ForYou Program established at the University of Missouri. ${ }^{2} 5615$ In addition, quantitative and qualitative evaluation methods were used to gain a greater understanding of programme implementation processes. Based on the results, it appears that it has been beneficial to have a well-structured organisational peer support programme for staff members after a stressful, patientrelated event. This is consistent with findings from other programmes. ${ }^{16-21}$ We developed tools to help evaluate effectiveness, including a peer responder self-evaluation that may be useful to other institutions in evaluating their current or future programmes. Another strength of the programme is that it provides a Health Insurance Portability and Accountability Act (HIPAA)-compliant alternative venue for discussions to take place, while protecting the privacy of patients and providers.

Our initial survey of employees supported the need for the programme. Most of the respondents to our baseline survey had experienced unanticipated adverse events, with subsequent personal problems, such as depressed mood, or concern about their ability to safely perform their job. The majority of these respondents mentioned that they did seek support and would prefer to speak with a colleague or peer, followed by their spouse/significant other, a friend or their supervisor. These results confirm the feelings of guilt, worry, helplessness, doubt and anger described by healthcare workers in previous studies. ${ }^{22}{ }^{23}$ Peer support emerged as the preferred mode of support for an institutional programme, also consistent with previous studies. ${ }^{6} 824$

Despite the compelling rationale for RISE, we encountered challenges in implementing the programme at a large academic medical centre. These included limited awareness of the magnitude and importance of the second victim problem, overcoming staff concerns about the confidentiality of the service, and risks of exposure to legal or disciplinary actions. The programme was supported and sanctioned by the hospital and has operated primarily with existing resources relying on the voluntary efforts of hospital staff. Financial limitations also reduced the capacity for formal mechanisms for data collection and monitoring.

The greatest challenge was getting staff members who could benefit from the programme to use it. During the pilot study, RISE received a relatively low volume of calls -only approximately one per month. Reports from these encounters suggested that some callers had been unaware of the programme, while others did not know how to activate an encounter. For that reason, after expansion of the programme hospital-wide, we launched a multipronged effort to increase awareness of the problem of the second victim, the availability of RISE, and that it was beneficial and safe to use. One successful initiative was adding a screen saver to publicise RISE to the small number of such ticklers that cycle continuously on the computer work stations across the medical centre. Formal presentations, particularly given in conjunction with departmental leadership on specific adverse events, appeared to be followed by an increased number of calls from related units. These presentations described the problem of the second victim, the availability of timely peer support, and the independent and confidential nature of the programme. We encouraged staff to speak up about events and how these events affected them personally ${ }^{22}$ and encouraged them to use support services-all part of the larger priority of developing a culture of safety within the organisation..$^{25}$ RISE was featured prominently on the cover of a widely distributed internal hospital magazine. Finally, several directors from units at increased risk for death and adverse events received RISE training in PFA, an action that also corresponded to more calls originating from those units. 
Table 5 Emergent themes from focus group

\begin{tabular}{|c|c|c|}
\hline Themes & Main findings & Descriptive quote \\
\hline $\begin{array}{l}\text { Peer responder training and } \\
\text { education }\end{array}$ & $\begin{array}{l}\text { Peer Responder Meetings: } \\
\text { Strengths: } \\
\text { Meetings were helpful to gain information and share insight } \\
\text { with peers } \\
\text { Benefitted from the activities, including the role-play scenarios } \\
\text { Case studies/interactions from other peer responders were } \\
\text { also helpful, especially stories related to 'non-ideal' scenarios, } \\
\text { such as anger from a family member } \\
\text { Opportunities for improvement.Second victim stories were too } \\
\text { de-identified and would like to hear more details about the event }\end{array}$ & $\begin{array}{l}\text { The biggest takeaway I got from the PFA training was the active } \\
\text { listening and the do no harm } \\
\text { I think a lot of the experiences that this type of training is modeled after } \\
\text { is military, firefighters, police-in which I have experience with } \\
\text { emergency medicine and firefighting-you are either completely bored } \\
\text { or there is maximum stress; there is no real in between. And so } \\
\text { decompressing or having an encounter after a police officer was short, I } \\
\text { think that is a much richer field to encounter. We have significant } \\
\text { stresses in the hospital on a daily basis, but hey are not the same kind } \\
\text { of thing. They are things that build over a period of time and then they } \\
\text { acutely explode in someone's face. How do you mold the training to the } \\
\text { environment we are in, which is not a disaster-based experience? } \\
\text { Hearing about how the [second victim] calls that have been handled } \\
\text { was helpful. } \\
\text { Sometimes getting more details on the event that happened would } \\
\text { allow me to say-this is how I would have done as a responder or this } \\
\text { is how I would have handled it. And even if that opens up the } \\
\text { discussion: this is the situation we have faced and ask others 'what } \\
\text { would you have said' and what are some of the things you would say to } \\
\text { that staff member. Then, the team can go through a debrief to discuss } \\
\text { the response. } \\
\text { The articles [current events] that we have gotten about nurse x, y, z } \\
\text { who has gone through something, committed suicide, or got fired from } \\
\text { her job; I think those are so powerful and they make us see how } \\
\text { important this programme is } \\
\text { I like to hear about what is going on with other second victims and it } \\
\text { makes you think about-if that person came to me, how would I } \\
\text { respond to them? } \\
\text { I think the debriefings are fabulous! I think that it's really important for } \\
\text { those who respond to have a place to process and get support from } \\
\text { their peers and get the validation that they did well, and they didn't do } \\
\text { any harm. And hearing how others responded is more training }\end{array}$ \\
\hline
\end{tabular}




\begin{tabular}{ll}
\hline Themes & Main findings \\
\hline $\begin{array}{l}\text { Emotional distress as a peer } \\
\text { responder }\end{array}$ & $\begin{array}{l}\text { Insufficient training for providing group support as opposed to } \\
\text { one-on-one support } \\
\text { Anxiety around not following up with a second victim or a unit } \\
\text { after an interaction }\end{array}$
\end{tabular}

\section{Descriptive quote}

What we did not take into account [when responding to second victims] are prior stress levels

When I did a group debriefing, it was very anxiety-producing because I had no idea what I was walking in to. I took one of my nurses with me and she sat with me for support and it ended up being fine

I would have trouble with not following up with the second victim after responding to them. And when you're a provider, you make a change in any patient's system, you follow up and make sure that that change was effective. And not having that opportunity to see if the 'patient' [second victim] is doing better as result, feels incomplete

Confidence in responding to Strengths: a second $\operatorname{victim}(s)$

- Different levels of confidence in responding to second victims

- More confident since they provided support as part of their current role

- More confident due to prior clinical training

Opportunities for improvement.

More comfortable in responding to second victims (one-on-one) as opposed to responding to an group

Recommendations for training
- Develop a mechanism to gather background information on event prior to interacting with second victim

- Provide more training on how to respond to groups

- Include content that is relevant to clinicians in hospital settings as opposed to PFA for relief workers

- Helpful for group debriefings to be less nurse-oriented and include an interdisciplinary approach

- Develop a debriefing mechanism to share the background of the event so that peers understand how the peer responder responded

Develop a list of key phrases peer responders can use in their interactions with second victims
From my very first day in nursing school, active and therapeutic

listening was a very big part of the nursing model. Most of us who have made it through nursing degrees are skilled at that already. As a provider, what cements my ability to do something well is to be able to do it time and time again

Training as a provider in general, is that you take from each portion of your training pieces that you will apply throughout your career. One thing I learned from my psychiatry rotation is the idea of therapeutic, thoughtful, and provocative listening. Thinking about events in the media through therapeutic listening is something I do now more than I do before

We are also getting a lot of requests for group debriefs

One thing that we did not get in any of our trainings was how to handle a group debriefing. And I think everybody would like that

It's interesting to see that there is a disparity in the responders in their own assessment in their ability to respond to a different group of people [responding to residents would be different than responding to nurses, for instance]

The role-play script helped me organize what I was saying [when responding to the second victim], which was like a map that tells me to start with this and do this

The role-playing helped people to feel more at ease Having the RISE binder and documents made me feel more secure [when responding to a second victim]

PFA, Psychological First Aid; RISE, Resilience In Stressful Events. 


\section{Limitations}

This study had several limitations. The first and greatest limitation involved the inherent conflict between the mission of assuring confidentiality for callers and the desire to evaluate the outcomes of encounters. Because of this, we did not collect identifiers on callers or follow up systematically with them. Instead, we measured success from the perspective of peer responders after their encounters with callers. Second, the data collection process evolved during programme implementation, so the data collection tools were, for the most part, not previously validated. Third, we have used a paper-based system for collecting responder encounter documents, and this has contributed to missing forms and data. We are now planning to implement a web-based document and with the capacity for real-time monitoring of missing data. Finally, we had relatively small sample sizes for the survey and the focus group, emphasising the need for continued evaluation.

\section{Implications for patient safety}

This study has practical implications for organisations interested in planning and developing formal provider support structures for employees to access after adverse events, and evaluating the results. Our experience and the tools included in this report should be helpful. There are also policy implications. For example, the Joint Commission and the National Quality Forum has now recommended healthcare institutions to recognise second victims' needs, and establish a support structure to assist them through coping with traumatic medical events. ${ }^{26}{ }^{27}$ Furthermore, this programme has attracted additional resources. The JHH and the Maryland Patient Safety Center have collaborated to develop guides for implementing a second victim support programme and measuring effectiveness-'Caring for Caregivers in Distress: Implementing RISE', and for training peer responders-'RISE Basic Training for Peer Responders.' The experiences of hospitals in Maryland and elsewhere that differ in size, teaching status and rural status should help to inform efforts to implement and adapt peer support programmes, so they can help the full range of healthcare workers that need them.

\section{Summary}

Hospital workers face many challenges following the occurrence of stressful, patient-related events. ${ }^{23} \mathrm{~A}$ few of these involve medical errors, but the large majority are simply related to the extraordinary stresses incumbent in the job. The lack of recognition of this problem, and the lack of support in the workplace may lead to additional adverse events and to further patient harm. To help support these providers and prevent them from burnout or leaving their clinical profession and the hospital, organisations should offer additional support to their employees. ${ }^{43}$ Committed leaders and the involvement of stakeholders representing disciplines and functional units across the institution were crucial to the development and implementation of the RISE programme at the Johns Hopkins. Despite a well-conceived and structured programme and a dedicated team of peer responders, there were relatively few calls in the first year. A sustained, multipronged campaign was required to increase awareness and trust among staff members, and to finally increase the volume of calls.

Acknowledgements The authors thank the RISE peer responders for their time and dedication in supporting their peers at the $\mathrm{JHH}$. The authors acknowledge the efforts and commitment of the Second Victim Advisory Board for championing the RISE programme throughout the JHH. The authors thank Dr George Everly for his generosity in providing PFA training to the RISE team, and Jeffery Natterman, JD for his guidance and advice with risk management and legal issues.

Contributors HE drafted the manuscript and provided substantial contributions to the acquisition and interpretation of the data. LP provided substantial contributions to the conception of the research and critically revised the manuscript for programme-specific content. CC critically revised the manuscript for programme-specific content relating to the development and structure of RISE. MN critically revised the manuscript for programme-specific content and tool development. HT contributed to the design of peer responder training and the programme framework. AWW oversaw the research, provided substantial contributions to the conception and design of the study, and critically revised the manuscript.

Funding This work was supported, in part, by the Josie King Foundation, and by the Maryland Patient Safety Center.

Competing interests None declared.

Provenance and peer review Not commissioned; externally peer reviewed.

Data sharing statement No additional data are available.

Open Access This is an Open Access article distributed in accordance with the Creative Commons Attribution Non Commercial (CC BY-NC 4.0) license, which permits others to distribute, remix, adapt, build upon this work noncommercially, and license their derivative works on different terms, provided the original work is properly cited and the use is non-commercial. See: http:// creativecommons.org/licenses/by-nc/4.0/

\section{REFERENCES}

1. Wu AW, Lipshutz AK, Pronovost PJ. Effectiveness and efficiency of root cause analysis in medicine. JAMA 2008;299:685-7.

2. Wu AW. Medical error: the second victim. The doctor who makes the mistake needs help too. BMJ 2000;320:726-7.

3. Kohn LT, Corrigan JM, Donaldson MS, eds. Committee on quality of health care in America, Institute of Medicine. To err is human: building a better health system. Washington (DC): National Academy Press, 2000.

4. Edrees $\mathrm{H}$, Federico $\mathrm{F}$. Supporting clinicians after medical error. BMJ 2015;350:h1982.

5. Edrees HH, Paine LA, Feroli ER, et al. Health care workers as second victims of medical errors. Pol Arch Med Wewn 2011;121:101-8.

6. Scott SD, Hirschinger LE, Cox KR, et al. Caring for our own: deploying a systemwide second victim rapid response team. $J t$ Comm J Qual Patient Saf 2010;36:233-40.

7. Krzan KD, Merandi J, Morvay S, et al. Implementation of a "second victim" programme in a pediatric hospital. Am J Health Syst Pharm 2015;72:563-7.

8. Pratt S, Kenney L, Scott SD, et al. How to develop a second victim support programme: a toolkit for health care organizations. Jt Comm J Qual Patient Saf 2012;38:235-40.

9. Ashbury FD, Cameron C, Mercer SL, et al. One-on-one peer support and quality of life for breast cancer patients. Patient Educ Couns 1998;35:89-100.

10. Joseph DH, Griffin M, Hall RF, et al. Peer-coaching: an intervention for individuals struggling with diabetes. Diabetes Educ 2001;27:703-10.

11. de Wit ME, Marks CM, Natterman JP, et al. Supporting second victims of patient safety events: shouldn't these communications be covered by legal privilege? J Law Med Ethics 2013;41:852-8. 
12. Brymer M, Jacobs A, Layne C, et al. Psychological first aid (PFA): field operations guide. 2nd edn. National Child Traumatic Stress Network and National Center for PTSD, 2006. http://www.ptsd.va. $\mathrm{gov} /$ professional/materials/manuals/psych-first-aid.asp (accessed 29 Nov 2015).

13. Everly GSJr, Barnett DJ, Links JM. The Johns Hopkins model of psychological first aid (RAPID-PFA): curriculum development and content validation. Int J Emerg Ment Health 2012;14:95-103.

14. Malterud K. Qualitative research: standards, challenges, and guidelines. Lancet 2001;358:483-8.

15. MITSS Clinician Support Tool Kit for Healthcare. http://www. mitsstools.org/tool-kit-for-staff-support-for-healthcare-organizations. html (accessed 29 Apr 2016).

16. Conway JB, Weingart SN. Leadership: assuring respect and compassion to clinicians involved in medical error. Swiss Med Wkly 2009;139:3

17. Seys D, Wu AW, Van Gerven E, et al. Health care professionals as second victims after adverse events: a systematic review. Eval Health Prof 2013;36:135-62.

18. Ullström S, Andreen Sachs M, Hansson J, et al. Suffering in silence: a qualitative study of second victims of adverse events. BMJ Qual Saf 2014;23:325-31.

19. Joesten L, Cipparrone N, Okuno-Jones S, et al. Assessing the perceived level of institutional support for the second victim after a patient safety event. J Patient Saf 2015;11:73-8.
20. White AA. Supporting health care workers after medical error: considerations for health care leaders. J Clin Outcomes Manag 2008;15:240-7.

21. van Pelt F. Peer support: healthcare professionals supporting each other after adverse medical events. Qual Saf Health Care 2008;17:249-52.

22. Wu AW, Folkman S, McPhee SJ, et al. Do house officers learn from their mistakes? JAMA 1991;265:2089-94.

23. Scott SD, Hirschinger LE, Cox KR, et al. The natural history of recovery for the healthcare provider "second victim" after adverse patient events. Qual Saf Health Care 2009;18: $325-30$

24. White AA, Brock DM, McCotter PI, et al. Risk managers' descriptions of programmes to provide emotional support for healthcare workers after adverse events. J Healthc Risk Manag 2015;34:30-40.

25. Marx DA. Patient safety and the "just culture": a primer for health care executives. Trustees of Columbia University, 2001.

26. Joint Commission on Accreditation of Healthcare Organizations. Looking at sentinel events along the continuum of patient safety. Jt Comm Perspect 2010;30:3-5.

27. National Quality Forum. Safe practices for better healthcare-2010 update: a consensus report [website], 2010. http://www.qualityforum. org/Publications/2010/04/Safe_Practices_for_Better_Healthcare_2010_Update.aspx (accessed 3 Jun 2015). 